\title{
CHAPTER 7. \\ POVERTY PROFILES OF ARTISANAL FISHERS: METHODS BASED ON THE SLA MODEL
}

\author{
FABIO PITTALUGA, EMILY CORCORAN, AND JEAN SENAHOUN
}

\subsection{WHAT IS A POVERTY PROFILE?}

The vast literature about poverty is organized around various ways of understanding this complex phenomenon. Income, exclusion/inclusion, levels of well-being, deprivation indices, access to material goods are only few of the conceptual tools that have been utilized as measures of poverty. The manner in which poverty is measured reflects fundamental assumptions as to its nature and causes (see Thorpe Chapter 2). Usually, poverty measurements and subsequent policy/programme implications, depend on what facets or angles of poverty are being addressed (Lok-Dessallien 1997)

The SFLP programme, funded by DFID, considers poverty to be a multidimensional and complex phenomenon, difficult to reduce to a single or a few indices for its measurement and representation. It is for this reason that, in order to understand the typologies, the depth, and the various dimensions of poverty situations, SFLP is producing poverty profiles that utilize the SLA approach as its conceptual framework and analytical tool. Utilizing the livelihood system as lens of analysis permits to identify the major factors that cause, aggravate or may potentially improve the poverty situation of a given group of poor people. The SLA, in fact, has the advantage of looking at virtually all aspects of poverty at once, evidencing what assets people have access to, what are the constraints limiting their access to different types of assets, and what are some of the potential options that may be available to improve their livelihoods. In addition, poverty profiles highlight the processes and trends that mediate people's access to different types of assets, as well as the external factors that are outside the control of a household that impact their livelihood options.

A poverty profile consists of the characterization, the localization, the enumeration and the description of groups of poor people. Such groups are defined according to the livelihood system they enact. The livelihood system includes the capabilities, the material and non-material resources, and the activities required for a means of living. The household 
constitutes the entry point and the principal unit of analysis. Thus, a livelihood-based group will be composed of families that share substantial common features in regards to their livelihood system, the constraints that limit the viability of their livelihood strategies, and the potential opportunities that may be available to them to improve their situation. Examples of livelihood-based groups of poor people analyzed in the course of pilot testing activities conducted in Benin and in Guatemala are: artisanal fishers, small-scale farmers in different agro-ecological zones, temporary laborers in urban and peri-urban areas. Thus, the approach is people-centered rather than area based, although location and distribution of poor and food insecure people are a crucial element in the profile.

Within a given livelihood system, however, not every household is subject to the same level of poverty. It is for this reason that livelihood-based groups are divided up into subgroups of people who enact different livelihood strategies within a livelihood system. For example, artisanal fishers of communities located in the South of Benin, have been classified into: a) manual laborers employed in fish-production activities; b) full-time fishers; c) fishers who diversify their livelihood strategies by practicing agriculture. Although all three categories belong to the livelihood system of artisanal fishers, each subcategory constitutes a relatively homogenous group of people whose poverty status differs from the others. Their specific poverty situation, furthermore, is the function of differential access to assets, and is differentially impacted by external factors.

\subsection{WHAT DOES A POVERTY PROFILE HIGHLIGHT AND WHAT INFORMATION DOES IT PROVIDE?}

Poverty profiles are analytical instruments directly linked to action, and are designed to provide information that may help in the formulation of actions to reduce poverty. Knowing how many people are poor in a given context is not sufficient to design appropriate actions to alleviate their poverty. Given that poverty is often a structural phenomenon, the nature of the measures that are needed to eradicate it must address problems at the same structural level. Thus, poverty profiles go beyond the enumeration of poor people per administrative unit (such as a head-count) and focus on the reasons why people are poor, and such reasons are often discernible in their livelihood systems.

Poverty profiles are not intended to be pure academic exercises, but rather to feed into decision-making processes at different levels both within and outside the scope of the SFLP programme. As such, poverty profiles are intended to provide relevant information for policy-making, planning, beneficiary targeting, and monitoring processes, among others.

One of the principal goals of SFLP is to reach the poorest communities or groups of artisanal fishers. In order to include them into the decision-making processes that drive induced change in their lives, some of the key questions that poverty profiles want to respond to, are the following: Who are the poor artisanal fishers in a given geographical area? How many are they? Where are they located? And why are they poor? Only by taking into consideration local perceptions of who, where and why people are poor, can actions be 
implemented that respond directly to the needs and wants of the communities of beneficiaries.

The basic structure of information contained in a poverty profile reflects the factors that influence livelihoods and the poverty situation of those being profiled. Such factors include:

- The variety of assets controlled by the household or to which the household has access;

- Mediating factors such as laws, policies, and regulations directly affecting the household, development programmes and projects operating in the area, and local attitudes and beliefs;

- External factors, such as demographic trends, the conditions of the natural resource base, and macroeconomic data;

- The probability of shocks, such as falling commodity prices, drought, conflict, or largescale illnesses.

By looking at the synergies between these factors and at the processes in which the communities are embedded, a poverty profile allows to understand the poverty context at large, understand the specific traits that characterize poor artisanal fishers' households, and identify the major factors generating or aggravating their poverty. By using census data and other sources of quantitative or qualitative data, a poverty profile also provides information on the distribution of poor artisanal fishers across a given space (community, water body, or country). Information about these aspects of poverty is often missing at the planning stage of an intervention, although it is crucial to ensure the efficacy of beneficiary targeting as well as the establishment of a baseline against which progress or change can be measured.

In order to be operational tools, poverty profiles need to be flexible in responding to the specific information needs of decision-makers in specific situations. Information needs vary according to the scale at which interventions are envisioned (national fisheries sector, water body, set of water bodies, community), as well as the type of actions that are foreseen (comanagement, micro-credit, capacity building). Thus, the focus of a poverty profile differs according to the domain of action envisaged, while the depth of information varies according to the scale of the intervention. On the other hand, when a specific type of intervention has not yet been defined, a poverty profile highlights the potential domains in which interventions are likely to succeed or not.

Because livelihood systems entail also opportunities for alleviating poverty, a profile highlights not only the causal factors of poverty and the constraints that people face, but also potential options that may be available within or outside the fisheries' sector for coming out of the cycle of poverty. If such options exist, they should be as sustainable as possible. The fieldwork conducted among communities of artisanal fishers on the Atlantic Coast of Guatemala, for example, evidenced that an improvement in artisanal fishers' access to better technology, with a consequent increase in fish-catch, was not an option. Neither was it a desirable solution for artisanal fishers themselves for their poverty status, who were deeply conscious of the impact of a steady human population growth on the natural resource base of the area. Given the constant reduction in fish stocks available, and the inadequacy of most of the coastal areas for small-scale agriculture, options for the improvement of their livelihood conditions consisted in the possibility of employment outside the fisheries' 
sector, or migration to other areas of the country. A livelihood system, in fact, is sustainable when it can cope with, and recover from, stresses and shocks, and yet maintain or enhance its capabilities and assets while not undermining the natural resource base (Carney 1998). This was not the case of the artisanal fishers on the Atlantic Coast of Guatemala.

\subsection{THE THORNY ISSUE OF VULNERABILITY}

In response to the World Food Summit's call for improved information systems about food insecurity, the Food Security Service at FAO developed methods to fulfill that request. Tackling the problem of food insecurity, in fact, entails the identification of those who are potentially vulnerable to become food insecure. Although food security is the result of complexly interrelated factors, as an outcome variable it may be considered a function of food consumption. This idea has been represented on a scale called "vulnerability continuum" (see annex 1) which utilizes the outcome variable of $\mathrm{kcal} / \mathrm{person} / \mathrm{day}$ as the index to establish cut-off lines between food-insecure, vulnerable, and food-secure people.

In poverty analysis, poverty lines are often calculated with reference to the average access to a minimum food basket. Thus, an argument could be made for the utilization of the food security "vulnerability continuum" as a proxy measurement of poverty status. In addition, the framework for food security analysis utilized in the context of vulnerable groups profiling, is very close to poverty analysis considering the fact that the SLA constitutes its underlying conceptual fabric. This argument, however, will not be made in this paper, because poverty is multifaceted, and vulnerability needs to relate to all component parts and to the systemic interactions between them (Chambers 1988, Jazairy et al. 1992, UNDP 1990). Thus, we cannot talk about vulnerability to poverty as such, but rather of a household exposure to shocks which can affect its poverty status, among which are natural disasters, physical insecurity, riskyness of livelihood strategies, economic crises, and political breakdowns (Davis 2001).

For the reasons highlighted above, a linear representation of poverty does not seem appropriate. The 5-asset pentagon utilized by the SLA conceptual model, however, could provide a more appropriate way of capturing and depicting the multidimensionality of poverty. Access to each asset type (human capital, social capital, physical capital, natural capital, and financial capital) could be measured utilizing a Likert scale which allows to transform qualitative measurements into quantitative ones. The five assets types can be considered as macro-variables composed of a series of micro-variables, e.g. statements that represent individual aspects of each macro-variable (see example in annex 2). This line of thinking, however, is still work in progress, and the principal problem to be faced is the weighting of both macro- and micro-variables. In fact, the relevance of access to natural capital for urban poor people is certainly lower than for farmers or fishers, while the relevance of health issues in a malaria-stricken zone are more relevant than at altitudes above $1500 \mathrm{~m}$. Furthermore, because poverty is a synergic outcome of multiple variables, setting a limit that defines cut-off lines between vulnerability and outright poverty constitutes an extremely difficult enterprise. 
In context of the SFLP poverty profiling exercises, vulnerability has not been calculated or associated with one given outcome (e.g. kcal/person/day), but rather explored according to local perceptions following which poverty-scales have been constructed. At the national level, such scales were built using expert opinions, while at the water body and community levels, scales were constructed on the basis of sub-national level expert opinion and focus groups with beneficiaries. In this latter case, fieldworkers also analyzed the terms used locally to define classes of poverty, highlighting the connotations embedded in the linguistic signs used in different communities. This permits to have a better understanding of the value systems that underlie the idea of poverty, identify some of the venues for social mobility, and possibly build scales comparable across communities. In the context of a preliminary evaluation of potential options for action, such information may lead to comprehend better what may be successful, and what may not be deemed as valuable in a given context.

Thus, in the context of poverty profiling exercises, accounting for, or measuring vulnerability to poverty, corresponds to understanding the structural and shock-mechanisms that are responsible for people's downward mobility along the locally perceived scales of well-being. Such mechanisms are dynamic and multidimensional and may provide better answers to the question of vulnerability than attempting to quantify indicators based on empirical, yet exogenous, observations.

\subsection{WHY A POVERTY PROFILE?}

At high political levels, only essential core of information relevant to a policy issue is needed. Maps, tables and charts that summarize more detailed information about an important issue are highly appreciated by such decision-makers. Information of this type often helps them to understand more clearly the nature of the problems needing to be tackled. It is also useful for building public awareness of people's needs and generating political support for relevant actions. However, if it is to be fully effective, such information must also provide a basis for action.

At the World Food Summit, for example, one representative of a Latin American country told of a very detailed poverty assessment that had been conducted in his country. At the conclusion of the assessment the government had available a precise count of the number of poor people in each district and municipality. This information was used to determine the allocation of public resources for a nationwide poverty alleviation programme. But when the additional funds reached the districts and municipalities, local officials had no information about who these poor people were or what kind of help they needed. So they simply allocated the additional funds to existing social programmes, in hopes that this might have some beneficial effect. In this example, geo-referenced information was successfully used to make a resource allocation decision, but the information was not adequate to make targeting decisions or to determine action priorities (Huddleston and Pittaluga 2000).

Early work on food security and poverty assessments tended to be geographically based and attempted to capture the depth and heterogeneity of these phenomena in a few 
indicators. Today, there is an emerging consensus among development practitioners that information about the livelihood systems of poor and food insecure people is pivotal to determine action.

Poverty profiles based on the analysis of livelihood systems enacted by artisanal fishers, fulfill a variety of information needs within SFLP, while they may constitute important documents to be integrated by national policy makers, other donors, or the communities of beneficiaries themselves. The pilot-testing experiences conducted in Benin and in Guatemala over the past year, evidenced that a distinction is essential between poverty profiles conducted at country or water body level and poverty profiles at community level. The two typologies imply differences in methodological paths utilized to collect data, as well as in the techniques chosen to elicit information. The two methodological paths will be illustrated in section 7.5 below.

The two typologies of poverty profiles differ primarily in regards to the size of population groups analyzed, their spatial distribution (nationally, at water body or set of water body levels, or community level), and the information needs that drive their compilation. Information deriving from a poverty profile at national or water body level may feed into policy and programming uses, while profiles of communities may feed into the planning of local activities, raising awareness and funds, and monitoring the impact of specific interventions. Section 7.5 below illustrates the methodological paths that have been followed for the compilation of both types of poverty profiles, while section 7.6 highlights some of the potential uses of information produced through poverty profiles at national, water body, or community level.

\subsection{METHODS FOR COMPILING POVERTY PROFILES}

Looking at the full range of artisanal fishers communities in a country or residing over a water body, and vice versa looking at a community of artisanal fishers are two fundamentally different exercises. This is because the patterns and the dynamics in which artisanal fishers are embedded are of a different nature. Such patterns and dynamics are the very elements that policy makers and development agencies need to grasp in order to design efficient and appropriate measures to alleviate poverty. Therefore two distinct methodological pathways have been constructed in order to capture better the nature of processes and dynamics that underlie artisanal fishers' livelihood systems at different levels.

\subsubsection{Poverty profiles at national or water body level}

In order to illustrate the national level itinerary followed for the compilation of a nationwide poverty profile for artisanal fishers, the case of Guatemala will be utilized. This case study was carried out by an international consultant with the help of a national consultant, under the umbrella of FIVIMS activities in May and June of 2000.

The method that was utilized has its underpinnings in the SLA conceptual model and attempts to capitalize on the wealth of knowledge and experience that is available within 
most countries, and it is relatively easy and quick to use. It has been particularly useful for obtaining a broad-brush picture of the underlying conditions and trends among poor and food insecure people in Guatemala, highlighting areas that need priority attention. The scope of the Guatemala exercise, however, went beyond an analysis of the artisanal fishing sector, and was geared towards the identification and analysis of all groups of people vulnerable to food insecurity in the country, among which are artisanal fishers. Nevertheless, the same method can be applied to a specific sector, asking similar questions (Who? How many? Why?) about a group of people classified according to a livelihood system (such as the artisanal fishers of a country or water body). The main steps of this methodological path are described briefly below.

\section{National brainstorming session}

The brainstorming session brought together stakeholders and other persons knowledgeable about poverty and food security issues in Guatemala. Participants included key ministerial technical officers (health, education, agriculture, environment, social planning), representatives of academic institutions and research centers, and representatives of nongovernmental organizations involved in the reduction of poverty in Guatemala. Participants identified all major groups of people in the country who were either food insecure or at risk of becoming so, and provided some information about where each group was located, their major sources of livelihood, and what were the perceived causes of their vulnerability to becoming food insecure.

Brainstorming session's participants constructed in a participatory way a comprehensive matrix identifying the principal groups that were considered to be vulnerable to food insecurity in Guatemala. This information was then triangulated with secondary sources and data available to validate the findings that emerged from the brainstorming session.

\section{Refinement of livelihood-based groups of poor people into relatively homogenous sub-} groups

As indicated in the discussion above, not all people belonging to a group defined by their livelihood system are equally poor or food insecure. For example, not all artisanal fishers in Guatemala were equally vulnerable to outcomes such as poverty or food security. Their conditions depended on the diversification of their income-generating strategies (petty commerce, agriculture), ethnicity, access to motorized boats, distance from markets, lack of basic services and infrastructure, and other issues. Such factors were utilized for a coherent classification of artisanal fishers into sub-groups of relatively homogenous families. As an example, artisanal fishers of the Atlantic Coast of Guatemala were divided into: households with no boats or non-powered boats fishing in lagoons or in the "barra" 1; indigenous households fishing in river estuaries; households of fishers diversifying income with production of coal on the mangrove forests.

The process that led to the definition of such groups was not a deterministic one utilizing statistical techniques (principal component analysis, factor analysis or others), but a

\footnotetext{
1 "Barra" is a local term that indicates where the rivers enter into open sea (estuary).
} 
participatory one. An additional set of brainstorming sessions was organized at departmental levels, separately for the Atlantic and the Pacific coasts which are intrinsically different. In each brainstorming session, the same set of open-ended questions was asked to participants. Participants to sub-national brainstorming sessions included local technical officers of key ministries, NGOs operating locally, and representatives of fishers' organizations. No organized groups of women existed to attend activities at this level.

Participants were asked to identify who were the extremely poor artisanal fishers and who were the ones close to coming out of the cycle of poverty. In the process, intermediate categories were also defined. Parameters utilized for the sub-division of artisanal fishers in a given department into sub-groups were selected by the participants themselves.

Brainstorming sessions were carried out by a three-man team of researchers, with different sectoral expertise (a socio-anthropologist, a veterinarian/nutritionist, and an agroeconomist), and aimed at eliciting information from locally knowledgeable resourcepersons. Questions posed to participants touched upon all categories of the SLA model. A moderator recorded such information on flip-charts, while the other two researchers took notes. Flip-charts turned out to be dynamic tools to record the results of each brainstorming session, and played a crucial role in visualizing the process of constructing the sub-group categories. As visual aids, they helped considerably in keeping discussions focused on the sub-groups, avoiding the uttering of general overall and unspecific statements. Purposefully, no standard questionnaire was utilized in an attempt to make the discourse flow as much as possible. Attention was also paid to avoiding potential déjà-vu bias in sessions subsequently held in nearby areas.

The latter part of the sub-national brainstorming sessions was devoted to the analysis of the strengths, weaknesses, opportunities and threats (SWOT) faced by one or more subgroups of artisanal fishers analyzed. This portion of the discussion was very important because it provided information as to what could be feasible and what, according to the perceptions of the participants, would be unlikely to succeed. In some instances, participants also identified specific institutions or bodies that could take up specific responsibilities in the fights against poverty and hunger.

The output at the end of sub-national brainstorming sessions consisted of a matrix in which sub-categories of poor artisanal fishers were identified, and a substantial amount of information organized by relatively homogeneous sub-groups and by the SLA model categories. This information constituted the basis for the analysis of poverty and food security of artisanal fishers in Guatemala.

\section{Validation of findings through selected field visits}

The decision to utilize representatives of institutions covering the areas where artisanal fishers were located rather than implementing a formal survey with beneficiaries themselves, was justified by the need to obtain information in a quick and cost-effective manner. In addition, resource-people of such institutions can often provide a good overview of the macro- and meso-dynamics in which artisanal fishers operate, as well as a historical context for present-day observable patterns. 
Nevertheless, the inclusion of ground-level information directly elicited from potential beneficiaries was considered crucial for the incorporation of bottom-up views into the analysis of artisanal fishers' livelihood systems, and as a mode for validating information elicited through sub-national brainstorming sessions. Thus, a series of sites were selected based on expert opinion estimates with the intent of covering different types of situations and aspects of artisanal fishers' poverty and food insecurity contexts, rather than to constitute a statistically significant sample.

Field validation visits consisted of a series of individual interviews with artisanal fishers and women, key people in the communities (school teachers, primary health centers' staff, religious leaders, village leaders, among others), as well as of focus group interviews with fishers' cooperatives and fishers' wives wherever possible. A semi-structured questionnaire was utilized to elicit information at this stage. The questionnaire covered all aspects of the SL model. PRA techniques were utilized to elicit information about seasonal patterns, geographical distribution of people and resources, calendars of productive activities by gender.

Findings from fieldwork were then incorporated into the profiles of the correspondent sub-groups of artisanal fishers that had been defined in the course of sub-national brainstorming sessions.

\section{Final validation of profiles}

Once the profiles had been compiled and the information from the different sources integrated into one single narrative, a workshop was organized to validate the structure of the profile, the correctness of statements reported, and the analytical conclusions drawn. The validation workshop was attended by a number of key informants representing institutions directly working with artisanal fishers or whose mandate included the provision of services to communities of artisanal fishers.

A Powerpoint MS ${ }^{\circledR}$ presentation was prepared to present the integrated findings to participants, following exactly the structure of the profiles. Copies of the profiles were also distributed to the participants in order to have full access to the integral version of the text to be validated. Because of timing problems, profiles could not be distributed in advance to the participants, although that could have probably improved the quantity and quality of comments received during the workshops.

Representatives of the institutions who attended reviewed each statement of the profile in an open forum. The process of jointly validating the profiles permitted to build a high level of ownership of the final document on the part of participants, an issue which is crucial in the potentiality of up-taking of findings in planning processes and the design of interventions. Furthermore, participants perceived the validation workshop as a way of building consensus among development practitioners across sectors about the issue of poverty and food insecurity of artisanal fishers. Last but not least, the workshop (and this methodological path in general) constituted a good venue for mainstreaming some of the SLA concepts and the SL approach in general. 


\section{Enumeration of artisanal fishers}

Estimates of artisanal fishers' population in Guatemala utilized for the compilation of the corresponding profile, were based on data from the population census of 1994, utilizing occupational codes that matched as close as possible the definition of artisanal fishers in that country (e.g. "peon pesquero" - ILO category 9213) ${ }^{2}$. The share of people in each subcategory, on the other hand, was determined in a qualitative manner by means of expert opinion, due to the lack of readily available data and the impossibility to conduct a survey for a more rigorous estimate.

\subsubsection{Poverty profiles at community level}

In order to illustrate the itinerary followed for the compilation of community-level poverty profiles, the case of South Benin will be utilized. These studies were carried out in two villages of small-scale fishers: Djègbadji, located on the lagoon along the coast of Benin, and Tchonvi, located on Lake Nokoué. The two villages were selected for an in-depth study of dynamics that may have larger significance at the level of the water body of which they are part.

The two case studies constituted a pilot testing of a methodology designed by the SFLP team in the Regional Support Unit of Cotonou, and the findings of the poverty profile were intended to promote fisheries co-management in South Benin's water bodies. Furthermore, the villages of Djègbadji and Tchonvi were selected because the livelihood systems encountered there are highly dependent on resources related to the water body, the remarkable level of poverty expected, and the distance from the region's main commercial center, i.e. Cotonou.

Poverty profiling exercises at community level are still a work-in-progress activity of the RSU team. The methodological path presented below, therefore, is to be seen as a pilot testing of an adapted form of the national and water body level method for poverty profiling, rather than a definitive solution. The following steps have been utilized to conduct poverty profiles at community level.

\section{Brainstorming session at village level with key resource people and secondary literature} review

The brainstorming session intended to elicit information about the larger context in which a community functions. As such, guided discussions centered around those processes that determine how the community is linked to other villages and to larger institutional frameworks. Attention was paid to the fabric of socio-economic relationships that connect (or fail to connect, or prevent to connect) the community to other social units, markets, and dynamics that are outside the control of the village under analysis. An in-depth secondary literature review of available literature and data was also conducted in order to contextualize preliminary findings.

\footnotetext{
${ }^{2}$ See International Labour Organization, Yearbook of Labour Statistics 2000. Geneva: ILO.
} 
Poverty profiles at community level can be flexible tools to respond to specific ad hoc end-user necessities (in this case the SFLP planning team). For example, the poverty profile currently under way in Guinée Conakry needs to feed into a larger technical study of the marine artisanal fisheries sector. Thus, brainstorming sessions were conducted with a special focus on the role of landing sites' dynamics vis-à-vis poverty.

\section{A 5-day fieldwork module for each community}

A team of 10 people, which included staff members of the RSU and the NCU, officers of Centre d'Action Régionale pour le Développement rural (CARDER) and members of NGOs operating locally, executed the 5-day module. Field techniques utilized were standard PRA tools, semi-structured interviews, interviews using open-ended questions, as well as focusgroup interviews. Focus groups were organized along gender and socio-economic lines, attempting to ensure participation from all social sectors of the communities analyzed.

Other than responding to the questions presented above (who are the poor? how many are they? where are they located? why are they poor?), during the 5 days spent in the village, a variety of PRA tools were utilized to:

- Construct a coherent scale of poverty based on the participatory exploration of local perceptions. In order to do this, linguistic analysis of the terms utilized locally by the indigenous languages was carried out, looking at the connotations embedded in the terms utilized to describe different states of poverty;

- Classify the local population into relatively homogenous sub-groups of families according to their livelihood strategies, and place them along the continuum of poverty emerging from discussions with the villagers;

- Understand what are the venues of social mobility along the locally constructed scale, both upward and downward. Understanding these dynamics is crucial for the identification of those factors accounting for people's vulnerability to poverty. Although such findings may be relevant only locally, they are fundamental to mitigate potential negative impacts of developmental efforts aiming at the alleviation of poverty;

- Understand the institutional environment in which small-scale fishers operate in order to pursue a given means of livelihood;

- Understand potential areas of conflict between different sectors of the community (or vis-à-vis other communities) in respect to accessing resources of the water body.

During the afternoon of the last day of fieldwork, preliminary results of the field investigations were discussed with the community assembly. A field report containing results of the two community-level studies is currently in the process of being drafted.

\subsection{USES OF NATIONAL OR WATER BODY LEVEL POVERTY PROFILES}

Information about poor artisanal fishers has important applications at many key decision points in policy and programming cycles for SFLP and for other stakeholders, such as the 
international donors' community and the national and sub-national authorities. Below are few immediate uses of information generated through poverty profiles carried out at national or water body levels.

Targeting interventions. Ensuring that SFLP activities are directed to the poorest communities of artisanal fishers requires a good understanding of the spatial distribution and of the typologies of poverty that can be tackled given its mandate and overall objectives. Poverty profiles provide geo-referenced information about the number of poor artisanal fishers per community, and the share of people belonging to each sub-group identified. This can immediately evidence priority areas for intervention, and become a basis for analysis of types of action to alleviate poverty.

Identification of potential actions. Poverty profiles are useful tools for detecting which activities have greater potential for success in contributing to the alleviation of poverty among communities of poor artisanal fishers. By providing an analysis of the institutional, natural, and economic environments in which communities of artisanal fishers operate, poverty profile allow to better contextualize potential actions in the domain of the feasible, as well as in the local context of desirable induced change.

Construction of baselines for future monitoring. Measuring the impact of interventions on livelihoods of a given population requires the definition of a baseline against which progress or change can be monitored. For this reason, poverty profiles provide a good tool for taking a snapshot of the poverty situation in a given geographic area at a point in time. From such a snapshot, furthermore, qualitative and quantitative indicators can be constructed in a participatory manner to account for change. Monitoring change in livelihoods, however, is difficult to boil down to few indicators, and often a narrative explanation of the reasons why change has occurred may better respond to the questions of causality. Nevertheless, attempts to construct indicators have been described in section 7.3 and are still pursued by the SFLP team.

Provide input for Policy, Institutions and Processes (PIP) papers. Poverty profiles entail an analysis of the so-called "mediating factors" that mediate artisanal fishers' access to assets. Such mediating factors include policies, programmes and strategic frameworks within which beneficiaries operate. Thus, poverty profiles may help in the identification of which policies, institutions, or processes impact upon artisanal fishers' livelihoods within or outside the fisheries sector. They may also help identify strategic entry point where changes in the policies, or the processes through which they are applied, might bring sustainable benefits in terms of poverty alleviation and livelihoods improvements (SFLP 2001).

Inclusion of artisanal fisheries sector in national poverty reduction strategies. Spatial distribution of poverty, together with an analysis of the causal factors generating it among artisanal fishers, provides important information for a specific sectoral focus on artisanal fisheries in the drafting of national poverty reduction strategies.

Information package for other donors involved in poverty alleviation efforts. Poverty profiles may be useful information products that feed into other donors' strategic planning to reduce poverty. In comparative terms, poverty profiles offer a vision of the types of interventions that have succeeded and the circumstances that have facilitated a positive outcome, as well as the types of actions that have failed and the best estimated reasons for 
such failures. Triangulating this information with geo-referenced information about the distribution of poverty among artisanal fishers, can provide a basis for priority setting among other donors.

\subsection{USES OF COMMUNITY LEVEL POVERTY PROFILES}

A snap-shot of poverty at community level may have multiple applications, towards the fulfillment of SFLP objectives, to ensure as much as possible a demand-driven type of development, and for the integration of community based information into larger information systems such the FIVIMS initiative.

Formulation of small projects for SFLP activities. Information about socially and culturally acceptable interventions may foster a higher level of empowerment of communities in the formulation of small-project proposals. Simultaneously, an in-depth understanding of the poverty issues relevant within the community and between contiguous communities may ensure a better planning of SFLP activities to reach the target beneficiaries in line with its overall mandate.

Formulation of co-management plans. Poverty profiles at community level provide information about the relationships between different institutions and the local civil society. They give also a snapshot of the heterogeneity of the communities across the lakes and lagoons in terms of livelihood strategies, traditional values, availability and nature of regulations for management as well as diversity within each community. All these are key issues for the promotion and execution of co-management activities.

Establishment of baseline information for monitoring purposes. In monitoring impacts of interventions, often a crucial shortcoming is the lack of a baseline against which change can be measured. Although measuring the causality of change is a difficult enterprise, having a baseline constitutes a preliminary condition for attempting to do so. When measuring impacts of interventions on livelihood aspects, qualitative indicators or narrative explanations of the dynamics of change constitute some of the best tools. Semi-quantitative indicators can also be developed on an ad hoc basis following the example given in section 7.3.

Risk and constraint analysis of potential interventions. An integral part of poverty profiles at community level is the analysis of past experiences and the analysis of the institutional framework in which the community operates. Information about what has worked in the past and what has not, as well as an analysis of the reasons why it did or did not, may provide important insights in the planning of new actions to reduce poverty. Similarly, poverty profiles provide information that may enhance the understanding of institutional constraints that may block or hinder the implementation of a given work programme at the micro level.

Identification of potential target groups for SFLP or other donors' activities. Poverty profiles provide a comprehensive classification of poor artisanal fishers into sub-groups of people by their poverty status. Each sub-category has specific livelihood characteristics, 
strengths and weaknesses that constitute important pieces of information in the identification of potential target groups for interested donors.

Mainstreaming of SL approaches at micro-level. The participatory process of constructing poverty profiles at community levels entail the possibility of transferring concepts and ideas of the sustainable livelihood approach to the micro-level. This is important not only for mainstreaming this ideology, but because it provides community based leaders, institutions, and decision-makers with a language for addressing the issue of poverty in the institutional domains of the donors' community.

Implementation of community-based information systems on poverty and food insecurity. Analysis of livelihood systems is now accepted as an effective starting point for classifying vulnerability, and permits such an understanding to develop. By integrating several dimensions of livelihood assets into broader, overall analyses, a clearer picture of risk emerges within communities or larger social units. To be effective, however, livelihood analysis requires a continuous flow of contextual information and knowledge reflecting the dynamic nature of any community or larger social aggregate. Poverty profiling may facilitate the realization of community-based poverty or food security monitoring systems with contextual data and the development of key indicators. SFLP is currently pursuing such an effort jointly with the SIFAR project, as a contribution to the larger FIVIMS initiative, in an attempt to enhance the synergies between micro-, meso-, and macro-information systems about food insecurity.

\subsection{CONCLUSIONS}

Poverty profiling exercises constitute a good instrument to analyze the distribution, nature, and depth of people's poverty. They provide a fairly quick and easy way of looking at complex dynamics, and as such they are cost-efficient. By answering the questions of who are the poor people, where they are located, how many they are, and why they are poor, poverty profiles provide important information for actions geared towards the alleviation of poverty and food insecurity.

Because poverty profiles are constructed in a highly participatory manner, they foster the level of institutional and community empowerment while aiming at ensuring full participation of stakeholders at different levels in the analysis of artisanal fishers' poverty. This enhances the level of ownership on the part of participating institutions - a key element for making sure that results and recommendations be adopted by the correspondent decision-makers.

Conceptually, poverty profiles place themselves in the larger literature that considers poverty to be a multidimensional phenomenon and that, as such, needs a multi-sectoral approach both in terms of analysis and action. The flexible nature of poverty profiles allows for an easy adaptation of the methods to specific needs of the end-users, thus becoming directly related to action. Furthermore, by capitalizing on the use of PRA tools and techniques, poverty profiles potentially maximize the impact of SFLP PRA training 
activities. Finally, they provide a snapshot of poverty status at different levels that can be used as baseline for monitoring and evaluation purposes.

As with all methods, also the poverty profiling methodology has weaknesses. Numerical wizards may criticize the methodology for its high reliance on qualitative information, especially in the effort to quantify the number of people belonging to the sub-groups of artisanal fishers analyzed. The risk of heavily relying on qualitative information, furthermore, is that the quality of analysis is to a large extent a function of the team's capacity to capture the complex nature of livelihood systems, and the depth of each issue raised during brainstorming sessions or during fieldwork activities. This risk is higher when the team is not familiar with the larger context in which the country, water body or community is set.

\section{REFERENCES}

Carney D., 1998. Sustainable rural livelihoods: what contribution can we make? Nottingham: Russell Press Ltd.

Chambers R., 1988. Poverty in India: concepts, research and reality. Discussion Paper 241. Brighton: Institute for Development Studies, University of Sussex

Davis B., 2001 (draft). Methods for poverty and food security mapping. Rome: Food and Agriculture Organization. FAO 2000. The state of food insecurity in the world. Rome: Food and Agriculture Organization

Huddleston B. and F. Pittaluga, 2000. Finding Out Who The Food Insecure Are, Where They Are Located, and the causes of their food insecurity. Rome: Food and Agriculture Organization.

Jazairy I., Alamgir M., and Panuccio T., 1992. The state of world rural poverty: an inquiry into its causes and consequences. London: International Funds for Agriculture Development and Intermediate Technology Publications.

ILO 2000. Yearbook of Labour Statistics. Geneva: International Labour Organization.

Lok-Dessallien R., 1997. Review of poverty concepts and indicators. UNDP poverty technical support document. New-York: United Nations Development Programme.

SFLP (Ghana NCU), 2001. The impact of policies, institutions and processes on fisheries livelihoods in Ghana. Accra: SFLP-NCU.

UNDP 1990. Human Development Report 1990: poverty. Oxford: Oxford University Press. 
Annex 1: The vulnerability continuum.

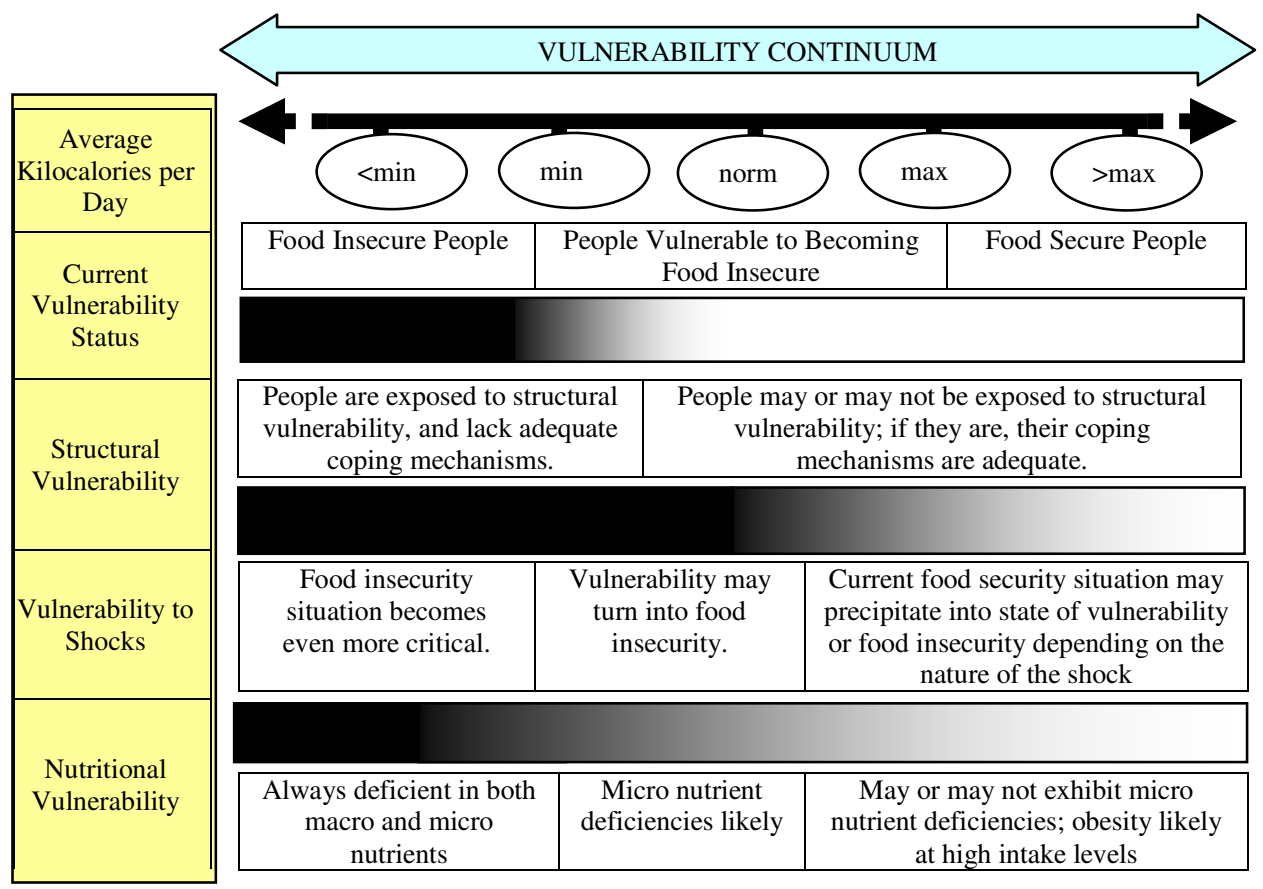


Annex 2: Example of construction of indicator for measuring impact on livelihood.

\begin{tabular}{|c|c|c|c|c|}
\hline \multicolumn{5}{|c|}{ Access to Social Capital } \\
\hline \multirow[b]{2}{*}{$\begin{array}{l}\text { HH resort to community leaders to resolve } \\
\text { conflicts }\end{array}$} & \multicolumn{3}{|c|}{ Qualitative evaluation } & \multirow{2}{*}{$\begin{array}{c}\begin{array}{c}\text { Numerical } \\
\text { score }\end{array} \\
3.3\end{array}$} \\
\hline & Nearly never & Sometimes & Often & \\
\hline $\begin{array}{l}\text { HH resort to social institutions (churches, NGOs) } \\
\text { as support services }\end{array}$ & Nearly never & Sometimes & Often & 6.6 \\
\hline $\begin{array}{l}\text { HH participate in community groups (cultural, } \\
\text { social) }\end{array}$ & Nearly never & Sometimes & Often & 9.9 \\
\hline $\begin{array}{l}\text { HH participate in groups with commercial } \\
\text { orientation }\end{array}$ & Nearly never & Sometimes & Often & 3.3 \\
\hline $\begin{array}{l}\text { Adults males participate in extension } \\
\text { activities/services }\end{array}$ & Nearly never & Sometimes & Often & 9.9 \\
\hline $\begin{array}{l}\text { Adults females participate in extension } \\
\text { activities/services }\end{array}$ & Nearly never & Sometimes & Often & 6.6 \\
\hline $\begin{array}{l}\text { HH receive support from social programs in need } \\
\text { situations }\end{array}$ & Nearly never & Sometimes & Often & 6.6 \\
\hline $\mathrm{HH}$ receives support from relatives or neighbours & Nearly never & Sometimes & Often & 3.3 \\
\hline $\begin{array}{l}\text { HH has access to information systems about } \\
\text { social services }\end{array}$ & Nearly never & Sometimes & Often & 6.6 \\
\hline $\begin{array}{l}\text { HH participate in activities of local committee for } \\
\text { development }\end{array}$ & Nearly never & Sometimes & Often & 6.6 \\
\hline
\end{tabular}

The macro variable "access to social capital" is divided up into ten observable microvariables. A numerical value is given to the macro-variable, say 99 , and each micro-variable accounts for $1 / 10$ of the total value of the macro-variable (vertical value assignment). Each micro-variable is also attributed a value depending on the qualitative evaluation of each statement, say 3.3 for red, 6.6 for yellow, and 9.9 for green. The total sum of the scores constitutes the relatively measured access to social capital vis-à-vis the total possible score, in the case above 62.7 over 99.9. Scoring all macro-variables using the same system allows representing the relative poverty status of one type of households on the pentagon, i.e. a multidimensional representation of poverty. 